\title{
The Impact of Sustainable Development on Eco-tech Architecture
}

\author{
Mahlegha ABDOLLAHI ${ }^{1}$ \\ Master of Architecture, Jolfa Branch, Islamic Azad University, Jolfa, Iran
}

\begin{abstract}
Being the requisite for progress and improvement, sustainable development as a process is the foundation for enhancement of the conditions and overcoming a lot of environmental shortcomings in developed societies. Sustainability should be the driving force behind moderate progress in all communities, especially in developing countries. In a general framework, sustainable architecture can be defined as creation of a man-made sustainable environment. Sustainable design in architecture is not a new style such as modernism or deconstruction; on the contrary, it is a way of thinking in design which is based on harmony with nature. The basis of Eco-tech architectural design is that the building is a small part of the surrounding environment; therefore it must perform as a part of an ecosystem and get incorporated into the life cycle. Ecotech architecture is a design in which people and the quality of interior spaces become specifically important. This is a descriptive-analytical research based on library studies. The effort is to study sustainable architecture and its place and impact on Eco-tech architecture. In this sense, sustainable architecture is itself a specific technology. The research findings point to the impact of sustainable development on nature and green architecture; the findings also point to the integration of sustainable architecture and Eco-tech design which can result in improvement of this huge industry in our country.
\end{abstract}

Keywords: naturalism, environment, sustainable architecture, Eco-tech architecture, green architecture

\section{Introduction}

Numerous definitions are put forward for sustainable development, but perhaps the simplest and the most comprehensive one pertains to Brundtland Conference in 1978 which defines is a the type of development which satisfies current needs without compromising the future generations' ability to satisfy their own needs (1).

Sustainable development is concerned with human survival and ultimate wellbeing. It interacts with all the cycles, dynamic processes, human resources, natural resources, and society's hardware systems. It seeks to build a bridge between present and future, human and nature, and justice and welfare both within and between generations (2).

Green architecture is an ancient process. An instance is when cavemen found out that caves facing south provide better temperatures that the ones facing north. Also in Iran, this process is

\footnotetext{
${ }^{1}$ Email address: afsane3716@gmail.com
} 
institutionalized in all the climates of the region. It has had numerous outcomes regarding sustainability and conservation of natural resources; therefore, the necessity for its review based on new approaches is not denied by the experts and scholars (3).

During his life on earth, man has always found the nature to be a bountiful and mysterious source. Ever since the dawn of humanity, man has sought to discover all aspects of nature, including the manifestation of nature in arts. Nature has always been a tremendous source of inspiration for mankind through out the history. As for architecture, by understanding the laws of nature and their application, man has been able to build structures with high efficiency and specific forms and compositions which make it beautiful (4). It can be said that for mankind, understanding nature is equal to understanding one's self. The saying by Monnet "I have never had any desire in my life except to become one with nature" can be a delicate metaphor for understanding the beauty of nature (5).

On that basis, the concept of nature in architecture, and the orientation toward nature in a sample of sustainable architecture works comprise the most important purpose of the present research.

\section{Research method}

Based on a documentary approach and using library studies, the present research collects the required data in the first step. The obtained information is then processed. In the end, using descriptive-analytical methods, the collected data is analyzed.

The research question is: what is the impact of sustainable development on Eco-tech architecture?

And the research hypothesis is: through different aspects, sustainable development affects Ecotech architecture.

On this basis, the problem is stated as below:

As we know, sustainable development generally refers to sustainability. This in turn leads to public welfare and peace. Sustainable development includes different factors such as green roofs, green walls, as well as the use of green buildings and construction materials. These factors have always affected architecture and been affected by it. In general, inspiration by nature can resist the soul-less and harsh environment. This responds to a part of modern human needs. In this research, we study different objectives of Eco-tech architecture such as energy efficiency, energy distribution, reducing the production of materials affecting human health, use of recyclable materials, detoxification, as well as the characteristics of green architecture and Eco-tech design on the path toward environmental sustainability which in turn leads to architectural sustainability.

The research background is based on the following work:

Title: Eco-tech architecture from theory to practice

Authors: Mohammad Latifi \& Naghmeh Alizadeh Gohari

Date and place of publication: 2009, the first conference of sustainable architecture.

The studied abstract is as below: 
Sustainable design is a way of thinking in design which is based on harmony with nature. This way of though has existed ever since centuries ago; for instance, Eskimos built their houses using the most environmentally abundant material i.e. ice and snow, with the most heat efficient form (hemisphere) in order to survive the harsh climate of the north pole. However, with the rush of technology and modernism, these methods were forgotten. The term "sustainability" was first introduced in 1986 by the global commission of environmental development and was defined as the type of development which satisfies current needs without compromising the future generations' ability to satisfy their own needs. This issue became important especially after the energy crisis and gained momentum day by day so as to find suitable strategies for people of the world. As for the application of sustainability and sustainable development in architecture, two important areas of expertise called Eco-tech architecture and green architecture are developed. The use of complex technology and ignorance toward environmental issues didn't last long; soon, subjects like coordination between architectural space and natural environment became the focus of attention and Eco-tech architecture eventually replaced Tech architecture. Considering Eco-tech architecture as a branch of sustainable development, the present research uses library studies to investigate into the concepts and principles of architecture of building as a part of the surrounding nature. In the next sections, some prominent works of sustainable architecture such as Hearst tower and Reichstag dome are introduced.

\section{Concepts and definitions}

\subsection{The importance of the environment}

The scientific speculation of the environment is as old as the science itself. Mankind stands at the brink of major transformation in the method of encounter with environmental issues. Therefore, it tries to lean toward the correct scientific basis in order to anticipate environmental problems. Today, the situation has changes considerably and the environment is accepted as a major social and political debate. Public surveys indicate that people around the world consider the environment as one the most important concerns (6).

\subsection{History of green architecture:}

Integration of architecture with nature and plants is not merely an idea. Green space design has been started ever since man paid attention to architecture. Design of the living place using areas such as the hanging gardens of Babylon is since known as an artistic method. Hanging gardens of Babylon including garden-like pillars and housings covered by trees all point out to the deep concern of the ancient man with architecture (7).

\subsection{Sustainable development and architecture:}

In this world, similar to other scientists, architects are also looking for solutions to provide mankind with suitable life conditions. It is obvious that life, work, recreation, rest, and etc. are among activities occurring in spaces designed by architects. Since the weaknesses and strength of a building affect the global ecology, architects have an extremely task at hand. The application of the concept of sustainability in architecture has opened up the discussion on subjects such as sustainable architecture, ecological architecture, green architecture, or environmental architecture; all of these have the same meaning and concept and refer to the kind of architecture compatible with the environment (8). 


\subsection{Green architecture from construction point of view:}

In recent years, numerous statements and articles by researchers have been released on the principles of green architecture. With little differences, most of these articles discuss subjects such as motivating the designers to conserve the energy and consider the characteristics of the working place or the location of the building and their surrounding areas. In their book titled "green architecture, a design for an energy-conscious future”, British architects Brenda and Robert Vale offered one of the simplest and explicit frameworks for green architecture. They introduce these principles using examples of building designs from Europe, England, and USA. Green architecture is an ancient process. An instance is when cavemen found out that caves facing south provide better temperatures that the ones facing north. The newer subject is to understand that green architecture is made by man and the best possible process for designing the buildings. In general, the green process suggests that all the issues are inter-dependent, and each decision should take all aspects into consideration (9).

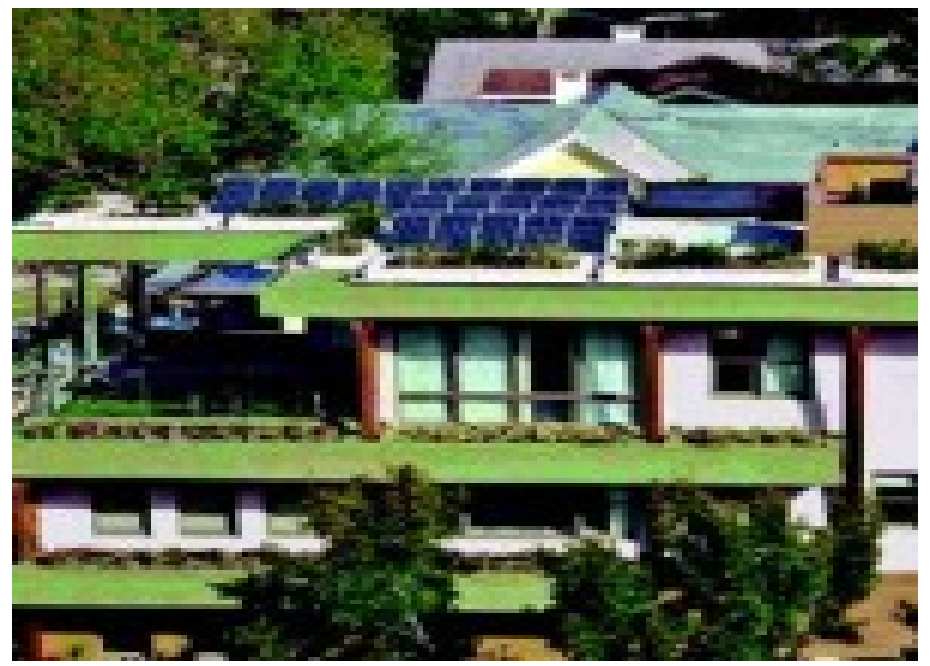

Picture 1: an example of green architecture

Some of the aspects of green architecture: increasing the welfare and wellbeing; the capacity for life and productivity; enhanced latency; maintenance capability; stabilization of the interior environment conditions; saving money by reducing costs of living; selection of green construction materials in order to protect the environment (10).

\subsection{Green house:}

It is a house designed in a sustainable manner and compatible with the environment, while at the same time focusing on efficient use of energy, water, and construction materials. The advantages of these houses are: use of natural energy, stabilization of the interior environment conditions, using suitable methods to prevent energy waste, control and optimize energy use, attention to specific climatic factors and features, use of recyclable chemical materials, and attention to the ecological characteristics of the region.

Significant issues in designing green houses are: selecting the orientation of the building with regard to natural conditions, privacy, wind, sunlight, noise reduction, attention to glass surfaces 
and internal lighting, use of thermal insulation in exterior walls, attention to window panes, and use of two-layered windows (11).

\subsection{Eco-tech architecture:}

The increasing and inevitable advent of industrial technology followed by electronic technologies made a group of architects and urban designers seek solutions to make peace between complex technologies and environmental issues and designs. The use of complex technology and ignorance toward environmental issues didn't last long; soon, subjects like coordination between architectural space and natural environment became the focus of attention and Eco-tech architecture eventually replaced Tech architecture. The use of high technology in accordance with environment is not and will not be the same in all structures. In some significant and specific architectural and urban structures, the latest technical innovations are used; this make it seem like the use of such innovations is not possible in developing countries in the contemporary era. However, the experience of European countries in some regards especially in small structures such as residential buildings may prove useful (12).

\subsection{Eco-tech and its relationship with nature:}

During consecutive centuries, the process of creating natural forms has been developed in order to reach solutions to deal with external factors such as climate, food accessibility, shelter, and etc. Natural forms and spaces are more comprehensive than what is created by man. The result of using natural forms in architectural design is the achievement of exquisite design in which structural efficiency, performance needs, and aesthetics are combined together. A structure should observe the laws of nature and respond to its requirement, while respecting the nature (12).

\subsection{Sustainable architecture:}

Sustainable development in construction activities are constructed environment is usually known as sustainable construction or sustainable structure. The construction sector is one of the largest economic and social sectors in Europe; along with structured environment, it significantly changes the natural environment. The construction sector and constructed environment are to key areas in global sustainable development (13).

As compared to other man-made structures, buildings are longer-lasting and affect sustainable development in all stages of planning, construction, equipment, demolition, or reuse. A building is a mixture of materials, substances, and combinations which are mutually effective. Moreover, buildings have a significant impact on human health. For instance, European people spend 90 percent of their time in buildings and architectural spaces (14).

\subsection{Definition of green architecture (sustainable architecture):}

Global warming, the diminishing of Ozone layer due to the use of polluters, increased environmental pollution, and extinction of natural species have attracted the attention toward environmental issues. In the meantime, development is known as one of the largest factors contributing to environmental changes. As a result, by using 50 percent of fossil fuels as a large industry, construction has lead to farmland destruction, soil erosion, environmental pollution, and threatening of public health, while intensifying the energy crisis. The environmental pollution 
crisis in the mid 1970s led to creation of pro-environment groups and the concept of sustainability was developed. The term "sustainability" was first introduced in 1986 by the global commission of environmental development and was defined as the type of development which satisfies current needs without compromising the future generations' ability to satisfy their own needs. This issue became important especially after the energy crisis and gained momentum day by day so as to find suitable strategies for people of the world. In recent years, numerous studies have been published regarding green architecture and sustainable architecture and its principles. These studies investigate the objectives and advantages and are focused on conservation of energy with regard to the features of the locations, building users, communities, and etc. (15).

\subsection{Sustainable design:}

Definitions provided for sustainable designs mostly focus on the idea of environmental sustainability in architecture; for instance, the following definition says: "a sustainable building is a structure which has the minimum incompatible effects on natural environment during its lifetime and in its regional and global implementation” (16).

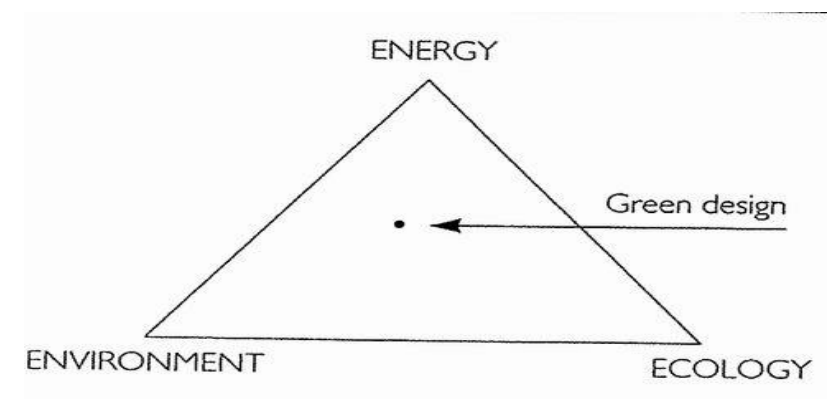

Figure 2: the three basic principles of sustainable architecture

\subsection{The role of green walls and roofs in achievement of sustainable design:}

The green roofs are sustainable, healthy, and provide the roof view which is one of the elements of today’s ecologic sustainable design. Green roofs (vertical gardens) are also a living cover system with benefits such as green roofs in which different plant species grow on the surface of building walls. These walls prevent the spread of dust in the air and protect the building against UV light, rain, and wind pressure. Therefore, alongside the nature and instead of fighting it, using solutions such as green roofs and walls assists sustainable architecture and urban design and reliable development, protects the environment, and helps the survival of human kind. Not only does not the green building harm the environment, it participates in the ecosystem in a positive way. Building green walls and roofs has now become an executive instruction for urban planning in most countries (12).

\section{Conclusion}

Considering the issues discussed in this article, it is concluded that today, alongside the advent of technology, sustainable development can make use of green architecture and Eco-tech design in order to enhance the wellbeing and welfare of the citizens. The use of green architecture or Ecotech is one of the components of sustainability wherein common concepts are followed. The process of construction is one of the most important factors contributing to formation of 
architectural approaches in different layers. If we use the components of green architecture such as Eco-tech design and green roofs and walls (vertical architecture) in designing and construction, we accomplish benefits such as energy efficiency, energy distribution, reducing the production of materials affecting human health, use of recyclable materials, and detoxification; this in turn contributes to sustainability in architecture, construction, and design. Also, the use of green architecture in itself attracts the public attention toward environmental issues which comprise other components of sustainable architecture. Therefore, it can be concluded that as an essential issue, the integration of Eco-tech architecture and sustainable development will bring forth public peace and welfare. On that basis, in order to accomplish good design and construction, commitment and expertise should accompany each other. If all things are considered, users are provided with an appropriate level of mental health (sustainable architecture) and a soothing environment.

\section{References:}

1. Wheeler S.M, Bately T, 2005, discussions on sustainable urban development, translated by Zaker Haghighi K, Tehran, ministry of housing and urban planning publication

2. Eyvazi M, 2006, human, the subject of development, Fars News Agency

3. Mousaei M, Ahmadzadeh M, 2009, developmental education and sustainable development, Rahoborde Yas periodical, No.18

4. Taghizadeh K, 2006, teachings on natural structures, lessons for architects, Honarhaye Ziba, No.28

5. Zarghami A, 2008, manifestation of natural truth in the process of landscaping, Honarhaye Ziba, No.35

6. Ardakani M, 2005, Ecology, Tehran University Press, 13-14

7. Dashti Shafiei A, 2010, study of the principles and position of green architecture in Iran and offering solutions for its development, the $2^{\text {nd }}$ national conference of construction and optimization of energy use through sustainable approach

8. Azerbaijani M, Mofidi M, 2003, the concept of sustainable architecture, collection of articles submitted to the conference of fuel consumption optimization in construction

9. Wilhelm ,m .d.(2005), green building spesifics ; costs ,benefits and case studies, pollution, prevention workshop for health ,ST . joseph hospital and medical center.2005

10. Zohouri Khosroshahi H, 2011, green architecture, an interpretation of new architecture, national conference of structure, roads, and architecture, 2-3

11. Lobber D, Watson D, Ghobadian V, 2004, climatic design, theoretical and practical principles for application of energy in construction

12. Sayadi E, Maddahi M, Mohammadpour A, Sustainable architecture,

13. CIB (1999), Agenda 21 on Sustainable Construction, Rotterdam: CIB Report Publication

14. WGSC, 2004 Working Group for Sustainable Construction (WGSC), (2004), Working Group

15. Soraei F, 2008, principles of designing green buildings, Behta Pajouhesh publication,

16. Nouhi H, 2003, Contemplating art and architecture 